\title{
Electrode Deterioration in Transmit-Receive Tubes ${ }^{1}$
}

\author{
By Judson C. French
}

\begin{abstract}
An investigation of the failure of a modified 1B24 TR (transmit-receive) tube revealed the cause to be the short circuiting of the pulsed keep-alive cathode to its anode, due to the formation of an unusual deposit on the cathode insulation and on the nearby anode surfaces. Analysis of the deposit showed that it originated at the cathode. To facilitate the investigation, diodes were constructed in which such parameters as distributed capacity, cathode material, current density and wave-form, and water vapor content of the gas fill could be readily varied while maintaining constructional features of the modified 1B24 relevant to the problem. The study disclosed that the glow discharge normally present breaks into a momentary arc, which by local heating of the cathode frees the metal that forms the deposit. Critical factors in the processes were determined, and by their proper control the deposit could be reduced or under some circumstances eliminated.
\end{abstract}

\section{Introduction}

The transmit-receive, or TR, tube is an essential element of many types of modern microwave systems. In a radar-type circuit it permits a single antenna to be used alternately by the transmitter and by the receiver. Its dependable operational life is of great importance not only to the operation of the system as a whole, but to the life of the receiver that it protects from the high power pulses of the radar's own transmitter and those of neighboring systems. Incidence of such a pulse upon the tube causes a radio frequency discharge in its argon- and water-vapor-filled resonant cavity. The discharge detunes the cavity; the resulting mismatch reflects the incident signal and the sensitive receiver is thus protected from burnout. The protection is sufficient only if the discharge occurs rapidly enough to prevent excessive power leakage to the receiver. To ensure this rapid breakdown, a small supply of ions is maintained in a critical region of the cavity by a direct current (or pulsed) glow discharge, the socalled keep-alive discharge. Failure of the keepalive discharge probably results in permanent damage to the receiver.

In a specialized version of a 1B24 TR tube, a deposit short circuiting the keep-alive discharge was found to form in a short time, ending the useful life of the tube prematurely. The investigation of the short circuit and remedial methods form the subjects of this paper. During the course of the investigation, it was found that breakdown of the glow discharge into an arc locally heated the cathode producing a metallic deposit that caused the short circuit. The extent of the deposit could be controlled by reduction of distributed capacity in the discharge circuit or by proper selection of cathode material. Current wave-form and density and the gas fill were also found to influence the deposit formation.

\section{The TR Tube}

The tube is illustrated in figure 1, a. The keepalive cathode surface is the circular end of the tapered portion of a cylindrical kovar rod (fig. 1, b and c). The rod is insulated along its length by 7052 glass,

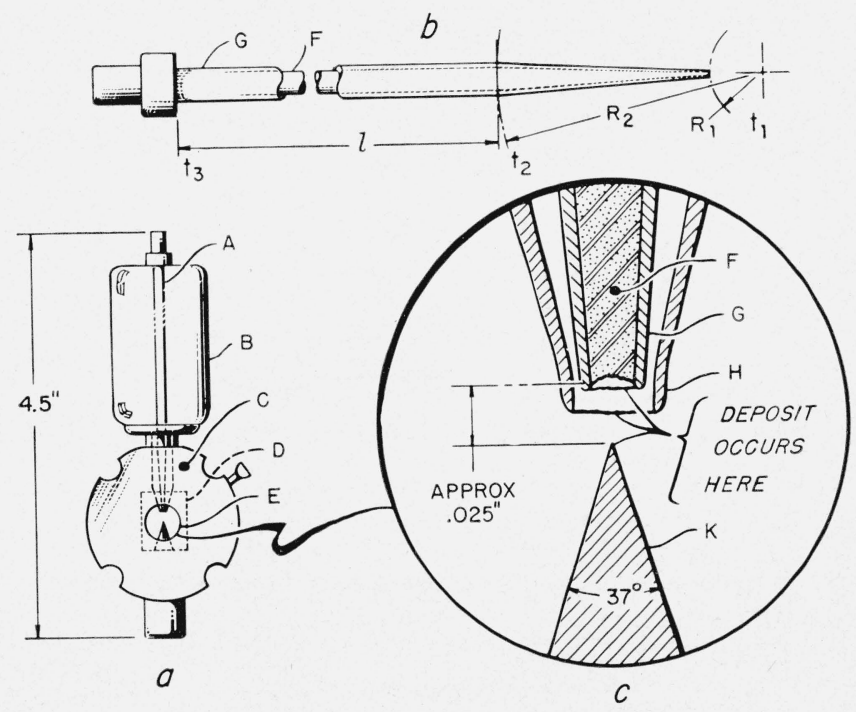

Figure 1. The modified 1B24 tube.

axterior view of the tube; $A$, keep-alive cathode lead; $B$, gas reservoir; $C$, Exterior view of the tube; $A$, keep-alive cathode lead; $B$, gas reservoir; $C$, copper tube-body; $D$, internal resonant cavity containing cones between which radio frequency disct

energy to resonant cavity.

b, The keep-alive cathode assembly; $F$, the kovar cathode lead; $G$, glass insulation sealed to cathode lead.

c, Cross section of cone tips in cavity; $F$, the kovar cathode lead; $G$, glass insulation sealed to cathode; $H$, hollow copper cone concentric to cathode serving as one keep-alive anode; $K$, solid copper cone serving as a second anode. The radio-frequency discharge occurs between cones $H$ and $K$ to detune the cavity.

which reaches its minimum thickness of 5 mils around the edge of the cathode face. Separation of the outer edge of the glass insulation from the concentric hollow truncated copper cone anode is not uniform, but in any event is of the order of several mils (fig. 1, c).

During certain phases of operation of the tube, the copper anodes are grounded while a negative potential applied to the cathode from a high impedance source produces a square wave of current. Current density at the cathode is about $5 \mu$ a per square mil. This abnormal glow discharge takes place in an atmosphere of argon and water vapor at a total pressure of the order of $10 \mathrm{~mm} \mathrm{Hg}$. Electrical and visual indications were that the short circuit limiting the tube life appeared between the kovar cathode and the concentric cone anode.

${ }_{1}^{1}$ This work was sponsored by the Bureau of Ordnance of the Navy Department. 


\section{Preliminary Investigation of the Short Circuit}

Short-circuited tubes were disassembled to permit visual study of the electrodes. This disclosed heavy deposits, as much as several mils thick, on the portions of the cones nearest the cathode and on the glass immediately surrounding the cathode surface. These deposits produced the short circuit at the point where they covered the edge of the insulating glass and bridged the gap between glass and concentric cone.

That the source of the material was the cathode itself was suggested by the fact that the cathode had been destroyed to a depth of 5 to 10 mils, leaving a bright surface rather uniformly covered with small pits. The pit diameters were of the order of $10^{-4} \mathrm{in}$. The suggestion was confirmed by spectroscopic analysis of samples of the deposited crust, which showed the principal constituents to be those of kovar, with the presence of small amounts of copper and silicon explained by their adherence to the crust when the latter was removed from the cones and insulation.

The deposits were of unusual character. They were brittle, of low density, and of irregular structure. Larger particles 5 mils thick on the cones appeared to be formed of small, smooth globules less than 1 mil in diameter. Filamentary structures built of similar small particles were also present. In no way did the deposit give the appearance of sputtered material

With sputtering of the cathode ruled out as the principal mechanism of the crust formation, another explanation was sought. The physical appearance of the cathode suggested one such explanation. This was that the cathode temperature exceeded the melting point of kovar, the molten surface then presenting a source of small droplets of metal, which by some means could be transferred to the surrounding areas, leaving behind the shiny, pitted cathode surface that was observed. To estimate the cathode temperature, it was assumed that cathode cooling was entirely by conduction, an assumption that proved reasonable since, at the cathode temperatures calculated, the heat loss by radiation was of the order of 1 percent of the total loss. Under this assumption, the tapered region of the cathode lead was treated as a conical portion of a hollow sphere (see fig. 1, b) of inner surface at temperature $t_{1}$, radius $R_{1}$; and outer surface at $t_{2}$, radius $R_{2}$. The fraction of the total surface of the sphere of radius $R_{2}$ intercepted by the tapered lead was equal to $A=2.4 \times 10^{-4}$ An approximate expression ${ }^{2}$ for the heat conduction through the cone per second is then

$$
h_{1}=\frac{4 \pi K R_{1} R_{2}}{R_{2}-R_{1}}\left(t_{1}-t_{2}\right) A .
$$

Here $K=0.046 \mathrm{cal} / \mathrm{cm}\left({ }^{\circ} \mathrm{C}\right)$ sec is the coefficient of heat conductivity for kovar. Neglecting conduction through the glass walls, $h_{1}$ is the flow also

\footnotetext{
${ }^{2}$ M. W. Fishenden and O. A. Saunders, The calculation of heat transmission (H. M. Stationery Office, London, 1932).
}

through the cylindrical portion of length $l$, radius $r$, of the cathode rod to the external lead at $t_{3}=30^{\circ} \mathrm{C}$, then

$$
h_{1}=\frac{K \pi r^{2}}{l}\left(t_{2}-t_{3}\right)
$$

Now the discharge conditions were such that the maximum power dissipated at the cathode was no greater than $0.15 \mathrm{w}$. Taking then $h_{1}=0.15 w=3.6 \times$ $10^{-2} \mathrm{cal} / \mathrm{sec}$, eq 2 may be solved for the temperature $t_{2}$ of the junction of cylinder and cone. Equation 1 then vields a cathode temperature $t_{1}$ of approximately $500^{\circ} \mathrm{C}$. This was $1,000 \mathrm{deg} \mathrm{C}$ below the melting point of kovar, precluding the melting of the cathode surface by this means.

Another and more promising explanation was that the abnormal glow might, due to some unknown surface conditions, break into an arc. Such an arc could be maintained for a short time despite the high impedance of the current source, if the tube leads, etc., provided sufficient distributed capacity to store the energy needed for the arc. Here would exist a means of locally heating the cathode, melting a small volume of the surface, and supplying the energy for its removal from the surface.

Heating of the cathode by this means has been discussed by Jurriaanse and Druyvesteyn ${ }^{3}$ in a study of the breakdown from a glow to an arc discharge. They have determined that such arcing in a gas at a pressure of the order of $1 \mathrm{~mm} \mathrm{Hg}$ requires a minimum energy storage of $2 \times 10^{-7} \mathrm{j}$ in the associated capacity. This makes necessary a capacity of the order of $6 \mu \mu \mathrm{f}$ at the voltages encountered in the tube under study. These voltages (150 to $200 \mathrm{v}$ ) were essentially the same as those encountered by Jurriaanse and Druyvesteyn $(150 \mathrm{v})$. Furthermore, arcing of this type was observed by these authors more frequently in argon than other noble gases; and oxidation of the cathode, quite likely to occur in the TR due to its water vapor content, was found to be essential to the breakdown.

With this in mind, distributed capacities of several tubes were measured with the tubes in place in the life test circuit, and typical values were found to be of the order of $20 \mu \mu \mathrm{f}$. This value is about three times the minimum reported by Jurriaanse and Druyvesteyn. Thus the voltage, capacity, and gas content of the modified 1B24 were certainly favorable for the production of arcs. It remained to be found if the energy in such arcs was ample for local melting of the cathode and removal of the molten drops, and also if the ares could be observed experimentally.

Under normal operating conditions stored energies of the order of $1 / 2 C V^{2}=4 \times 10^{-7} \mathrm{j}=10^{-7}$ cal existed in the distributed capacity. This energy was sufficient to raise to the melting point and fuse a mass $M$ of the cathode material, found by the expression

$$
1 / 2 C V^{2}=M h_{s}\left(t_{m p}-t_{1}\right)+M h_{f} .
$$

The specific heat $\left(h_{s}\right)$ and heat of fusion $\left(h_{f}\right)$ of kovar were not available. Taking $h_{s}=0.16 \mathrm{cal} / \mathrm{g}$ deg $\mathrm{C}$

${ }^{3}$ T. Jurriaanse and M. J. Druyvesteyn, Physica 3, 825 (1936). 
and $h_{f}=48 \mathrm{cal} / \mathrm{g}$, which are the values for iron, the most abundant component of kovar, $M$, was found to be $5 \times 10^{-10} \mathrm{~g}$. This mass of iron would occupy a hemispherical volume of diameter $d_{1}=2 \times 10^{-4}$ inch, which was of the order of magnitude of the pits observed on the cathode surface.

The energy for removal of the molten metal was estimated by a calculation of the change in surface energy of the fluid (surface tension $X$ area) as the surface area of the $M$ grams of cathode material was increased during removal. The small molten mass was assumed to occupy a hemispherical region at the cathode surface having an exposed area $\pi\left(d_{1} / 2\right)^{2}$. Upon removal, the mass was considered to assume a spherical shape of area $4 \pi\left(0.794 d_{1} / 2\right)^{2}$, leaving behind a hemispherical pit whose exposed area was $2 \pi\left(d_{1} / 2\right)^{2}$. The factor 0.794 arises from the fact that the volumes of sphere and hemisphere were equal. A value of surface tension $(S=1,500$ dyne $/ \mathrm{cm})$ not likely to be exceeded by the cathode material was chosen. The energy required, $E=4 \pi S \quad\left[d_{1}^{2} / 8+\right.$ $\left.\left(0.794 d_{1} / 2\right)^{2}-\left(d_{1} / 4\right)^{2}\right]$ ergs, was found to be $4 \times 10^{-11}$ cal. This was quite negligible by comparison with the energy available in a single arc discharge. The energy to carry the mass from cathode to anode was even smaller, of the order of $10^{-15} \mathrm{cal}$.

Visual and oscilloscopic observation of the glow discharge in the tubes showed conclusively that such arcs did occur, the discharge voltage dropping during the readily visible arcs as was expected. Old tubes operated on direct current showed bursts of ten to twenty arcs, spaced at 5 minutes to an hour or more apart. The pulsed tube yielded ares in groups of one or two per pulse for several pulses at irregular intervals. No statistical study of arc frequency was made, but it was established that the frequency was considerably higher than the average required to supply the deposit at a rate of $M$ grams per arc.

\section{The Experimental Diodes}

To learn more of the parameters affecting the arcing, diodes were constructed with which to determine whether certain factors were important in the formation of arcs or deposits and whether arcing was essential to the formation of the deposits. The factors were distributed capacity, cathode diameter and material, pulsing of the discharge current, water vapor in the gas fill, and shape of the anode. Electrodes of various types were used, but in all cases they were arranged as in figure 2. This represented a considerable simplification from the modified 1B24 construction, but preserved the characteristics of its construction such as cathode shape, area and insulation, and electrode spacing, essential to the problem. An advantage of the construction was that the inherent capacity in the tube was less than $1 \mu \mu \mathrm{f}$. Additional capacity could be connected externally between cathode and anode in any amount desired.

As may be observed in figure 3, four different cathode types were used: $0.030 \mathrm{in}$. and $0.020 \mathrm{in}$. kovar glassed over except at the cathode face by about 0.030 in. of 7052 glass, 0.020 in. kovar, and 0.020 in. $18-8$ stainless steel insulated by porcelain

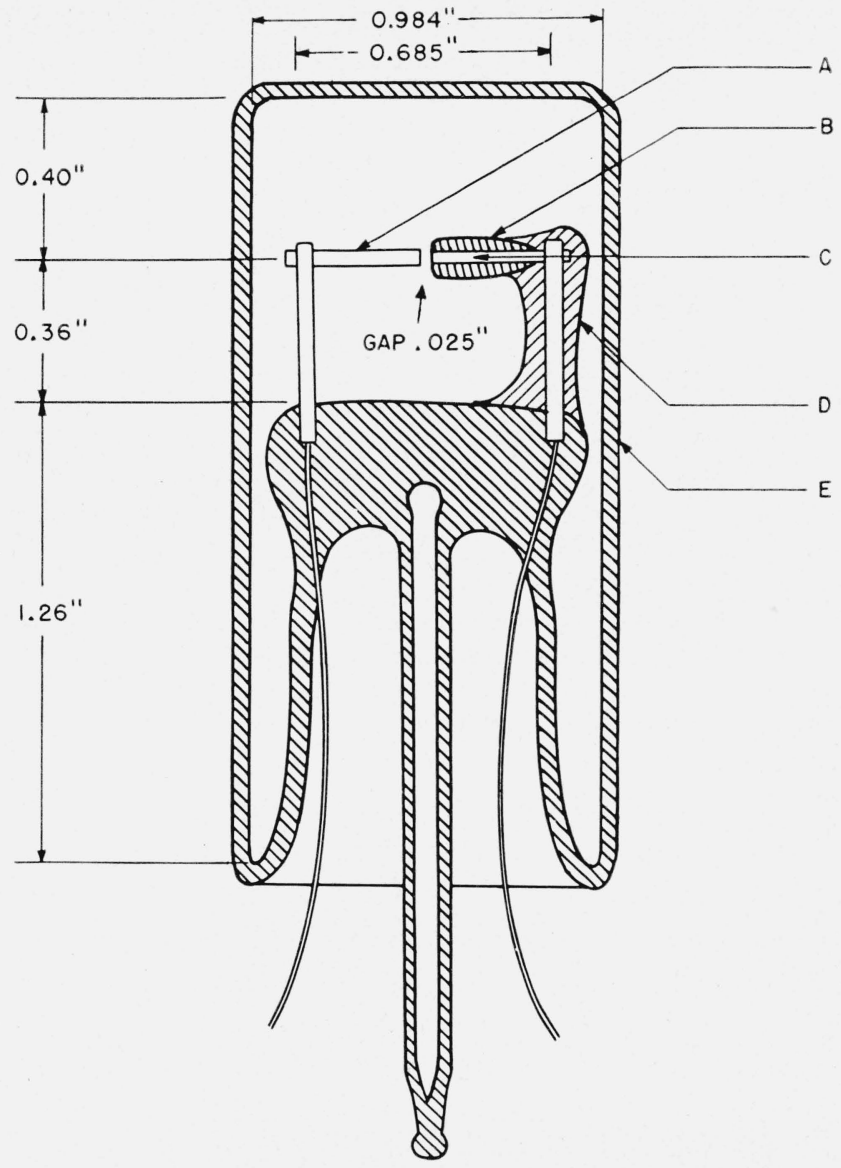

Figure 2. Experimental diode number 2.

$A$, anode 0.040 -in. Ni rod; $B$, cathode insulation, 7052 glass; $C$, cathode, 0.030 -in kovar rod; $D$, support insulation, Sauereisen number $78 ; E$, envelope and press kovar rod; $D$
of soft glass.

tubing. Anodes were all of grade A hydrogen fired nickel. These were 0.030 in. or 0.040 in. in diameter with either a flat face or a conical point similar to a 1B24 cone tip.

Table 1 shows the combinations in which the variables listed above were studied in relation to deposit rate. In the table, all variables within a group are held constant except those designated by bold-faced type. It is suggested that a relation between the varying parameters and the deposit resulting may be obtained readily by observing the bold-faced data and the corresponding brief description of the deposit in the right-hand column.

It may be noted that in each group there was a repetition of important combinations from the preceding group of tubes, which obviated concern over variation of conditions from group to group of tubes. Indeed this demonstration of consistent results from group to group indicated that comparison between the groups was permissible, yielding more extensive information than the bold-faced data suggest. However, the data printed in bold face is adequate for this discussion.

Ten of the tubes were operated under direct current conditions, while the remaining twenty were 
TABLE 1. Cathode deposits produced in the experimental diodes

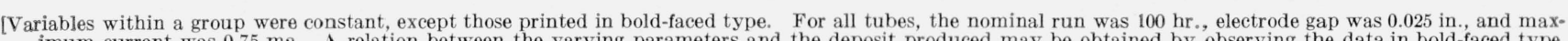

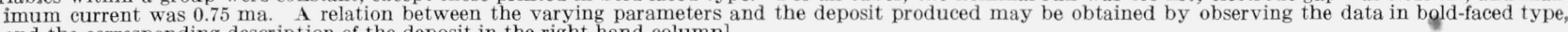
and the corresponding description of the deposit in the right-hand column]

\begin{tabular}{|c|c|c|c|c|c|c|c|c|c|c|}
\hline \multirow{2}{*}{ Group } & \multirow{2}{*}{ Tube No. } & \multicolumn{3}{|c|}{ Cathode } & \multicolumn{2}{|c|}{ Anode (Ni) } & \multirow{2}{*}{ Gas fill } & \multirow{2}{*}{ Capacity } & \multirow{2}{*}{$\begin{array}{l}\text { Current } \\
\text { type }\end{array}$} & \multirow{2}{*}{$\begin{array}{l}\text { Deposit (brief } \\
\text { description) }\end{array}$} \\
\hline & & Material & Insulation & Diameter & Shape of face & Diameter & & & & \\
\hline 1. & $\left\{\begin{array}{l}2,8 \ldots \ldots \\
9 \\
4,5\end{array}\right.$ & $\begin{array}{l}\text { Kovar } \\
\text { do }\end{array}$ & \begin{tabular}{|} 
Glass $\ldots . .$. \\
do do
\end{tabular} & $\begin{array}{r}\text { in. } \\
0.030 \\
.030 \\
.030\end{array}$ & Flat & $\begin{array}{r}\text { in. } \\
0.040 \\
.040 \\
.040\end{array}$ & $\begin{array}{l}\mathrm{A}+\mathrm{H}_{2} \mathrm{O} \\
\mathrm{A}+\mathrm{H}_{2} \mathrm{O} \\
\mathrm{A}+\mathrm{H}_{2} \mathrm{O}\end{array}$ & $\begin{array}{r}\mu \mu f \quad 0 \\
\mathbf{5 7 0} \\
\mathbf{1 , 1 0 0}\end{array}$ & $\begin{array}{l}\mathrm{d}-\mathrm{c}_{\ldots} \\
\mathrm{d}-\mathrm{c}_{\ldots} \\
\mathrm{d}-\mathrm{c}_{\ldots}\end{array}$ & $\begin{array}{l}\text { Negligible. } \\
\text { Very small. } \\
\text { Small. }\end{array}$ \\
\hline $2 \ldots$ & $\left\{\begin{array}{l}11 \\
14-\ldots- \\
12\end{array}\right.$ & \begin{tabular}{l} 
do \\
\hdashline \\
\hdashline
\end{tabular} & \begin{tabular}{|}
$\ldots$ do \\
$\ldots$ \\
$\ldots$
\end{tabular} & $\begin{array}{l}.020 \\
.020 \\
.020\end{array}$ & 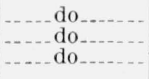 & $\begin{array}{l}.030 \\
.030 \\
.030\end{array}$ & $\begin{array}{l}\mathrm{A}+\mathrm{H}_{2} \mathrm{O} \\
\mathrm{A}+\mathrm{H}_{2} \mathrm{O} \\
\mathrm{A}+\mathrm{H}_{2} \mathrm{O}\end{array}$ & $\begin{array}{r}0 \\
570 \\
1,150\end{array}$ & $\begin{array}{l}\text { d-c.... } \\
\text { d-c.... } \\
\text { d-c. }\end{array}$ & $\begin{array}{l}\text { Negligible. } \\
\text { Small. } \\
\text { Moderate. }\end{array}$ \\
\hline $3 \ldots$ & $\left\{\begin{array}{l}16,19 \ldots \ldots \\
20 \\
17,18 \\
21\end{array}\right.$ & $\begin{array}{l}\text { do } \\
\text { do } \\
\text { do }\end{array}$ & $\begin{array}{l}\ldots \text { do } \ldots \ldots \ldots \\
\ldots \text { do }\end{array}$ & $\begin{array}{l}.020 \\
.020 \\
.020 \\
.020\end{array}$ & $\begin{array}{l}\ldots \\
\ldots\end{array}$ & $\begin{array}{l}.030 \\
.030 \\
.030 \\
.030\end{array}$ & $\begin{array}{l}\mathrm{A}+\mathrm{H}_{2} \mathrm{O} \\
\mathrm{A}+\mathrm{H}_{2} \mathrm{O} \\
\mathrm{A}+\mathrm{H}_{2} \mathrm{O} \\
\mathrm{A}+\mathrm{H}_{2} \mathrm{O}\end{array}$ & $\begin{array}{r}0 \\
0 \\
1,100 \\
1,100\end{array}$ & $\begin{array}{l}\text { Pulse } \\
\text { d-c } \\
\text { Pulse } \\
\text { d-c }\end{array}$ & $\begin{array}{l}\text { Negligible. } \\
\text { Do. } \\
\text { Very large. } \\
\text { Moderate. }\end{array}$ \\
\hline $4 \ldots$ & $\left\{\begin{array}{l}24,25 \ldots \\
22,23 \\
26,27\end{array}\right.$ & \begin{tabular}{l} 
d... do \\
\hdashline do
\end{tabular} & 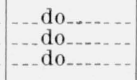 & $\begin{array}{l}.020 \\
.030 \\
.030\end{array}$ & $\begin{array}{l}\text { Pointed } \\
\text { Pointed } \\
\text { Flat }\end{array}$ & $\begin{array}{l}.040 \\
.040 \\
.040\end{array}$ & $\begin{array}{l}\mathrm{A}+\mathrm{H}_{2} \mathrm{O} \\
\mathrm{A}+\mathrm{H}_{2} \mathrm{O} \\
\mathrm{A}+\mathrm{H}_{2} \mathrm{O}\end{array}$ & $\begin{array}{l}1,100 \\
1,100 \\
1,100\end{array}$ & \begin{tabular}{l} 
Pulse \\
\hdashline do
\end{tabular} & $\begin{array}{l}\text { Very large. } \\
\text { Large. } \\
\text { Do. }\end{array}$ \\
\hline & $(28,30,32 \ldots$ & 18. 8 steel... & Ceramic & .020 & Pointed...... & .040 & $\mathrm{~A}+\mathrm{H}_{2} \mathrm{O}$ & 1,100 & ............... & Negligible, except \\
\hline $5 \ldots$ & $\left\{\begin{array}{l}29,31,33 \ldots \\
35 \\
36,37 \\
34\end{array}\right.$ & $\begin{array}{l}\text { Kovar.... } \\
\text { Kovar.... }\end{array}$ & $\begin{array}{l}\text { Ceramic } \\
\text { Glass } \\
\text { Glass } \\
\ldots \text { do }\end{array}$ & $\begin{array}{l}.020 \\
.020 \\
.020 \\
.030\end{array}$ & 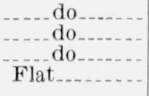 & $\begin{array}{l}.040 \\
.040 \\
.040 \\
.040\end{array}$ & $\begin{array}{r}\mathrm{A}+\mathrm{H}_{2} \mathrm{O} \\
\mathbf{A}+\mathbf{H}_{2} \mathrm{O} \\
\mathbf{A} \text { only } \\
\mathrm{A}+\mathrm{H}_{2} \mathrm{O}\end{array}$ & $\begin{array}{l}1,100 \\
1,050 \\
1,050 \\
1,050\end{array}$ & $\begin{array}{l}\ldots \text { do } \\
\ldots \text { do }\end{array}$ & $\begin{array}{l}\text { Largest obtained. } \\
\text { Very large. } \\
\text { None. } \\
\text { Large. }\end{array}$ \\
\hline
\end{tabular}

CATHODES
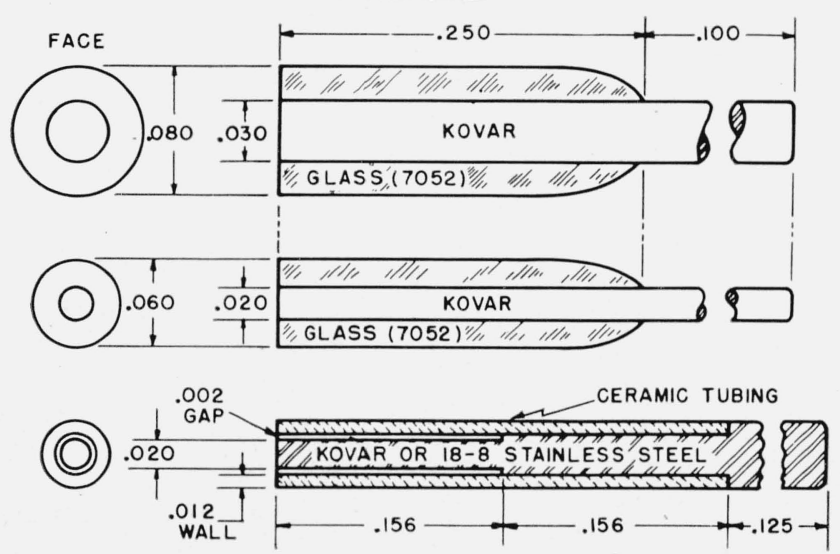

ANODES

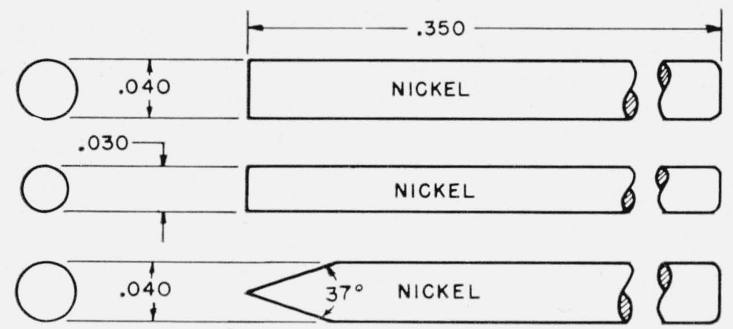

Figure 3. Electrode types used in experimental diodes.

Dimensions are in inches.

pulsed, using a thyratron circuit to provide a quarter sine wave of current with fast rise and sinusoidal decay at a $60 \mathrm{c} / \mathrm{s}$ repetition rate.

During the arc, extra current was drawn momentarily from the pulser due to reduced tube resistance. This produced a pip super-imposed on the quarter wave trace obtained by connecting an oscilloscope across a resistor in series with the tube, thus indicating the occurrence of the arc. The arc rate and capacitor energy were found to be in proportion to the deposit in cases where these factors were measured.

The gas fill was the same as that in the modified $1 \mathrm{~B} 24$ with the exception of the series in which water vapor was omitted to study its effect upon the deposit. Each of the tubes was run approximately $100 \mathrm{hr}$.

It was established that arcing occurred in the diodes at the capacity measured for the 1B24. Larger values were used in the runs, however, to increase the size of the deposits and to make their comparison easier, as deposit measurement was accomplished by tracing enlarged shadowgraphs of the electrodes seen on a microcomparator before and after the run.

Figure 4 presents sample tracings obtained from the shadowgraphs before and after 100-hr runs. On these may be seen the irregular conductive deposits, which, as the cathode deteriorates, build up on the insulator surrounding the cathode to provide the shorting bridge.

\section{Discussion of Diode Results}

Early experiments established that the deposits observed in the diodes were proportional to the arc rates in these tubes. Thereafter, the deposit shadowgraph made at the end of a 100-hr run was used as an indication of the total number of ares that had occurred in a given tube. An occasional check on are rate, however, was maintained visually during the runs. By study of a tabulation of the varying parameters similar to table 1 , together with a complete series of shadowgraphs for the tubes, it was possible to determine the principal factors in the formation of the short circuiting deposits. 


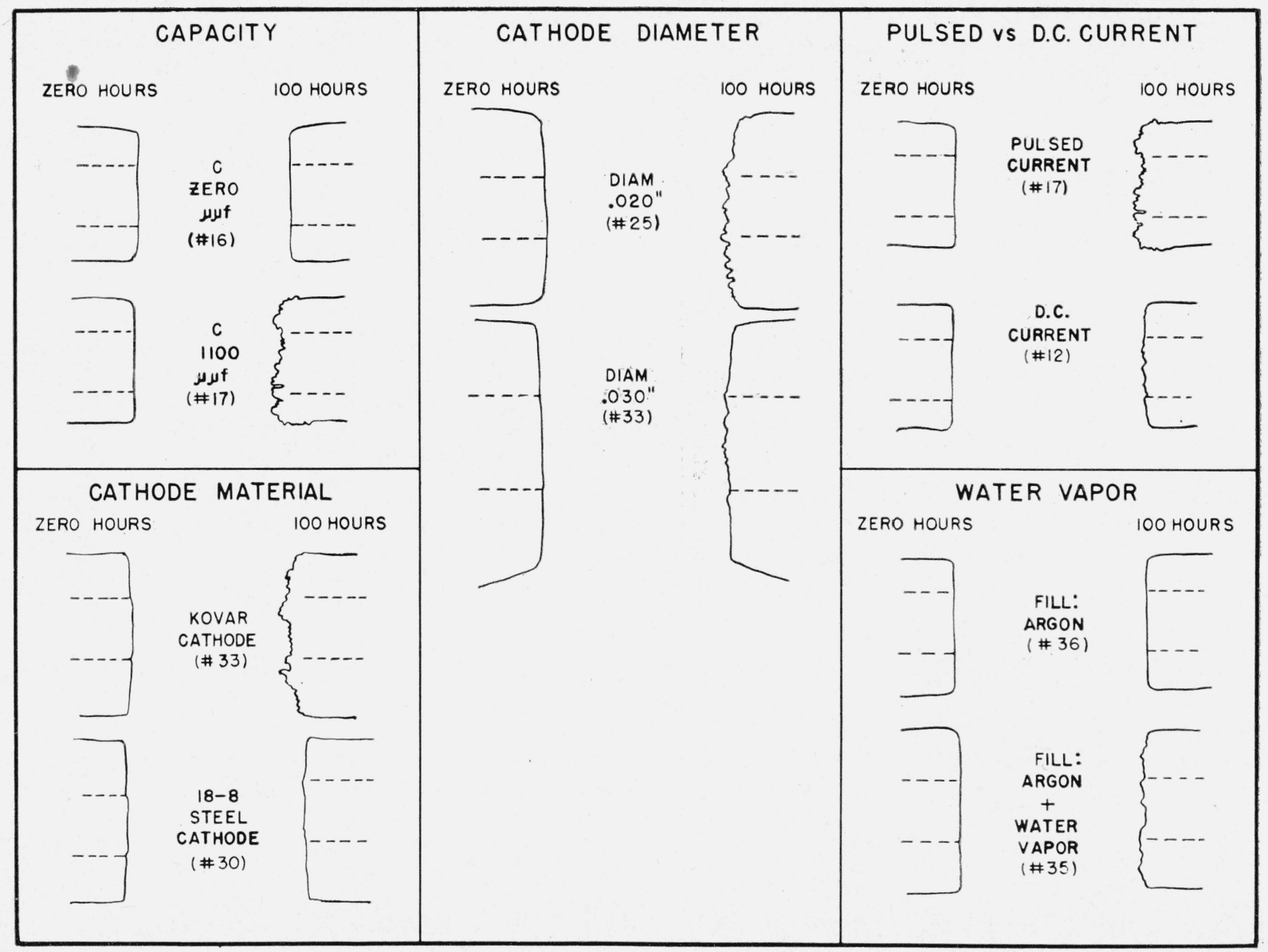

FIGURE 4. Examples of cathode tracings.

Microcomparator tracings of cathode profiles at the beginning and end of a 100-hr run show the effects produced on the deposit by variation of five tube parameters Dotted lines indicate the location of the cathode conductor within its insulation.

1. In the absence of external capacity when the total capacity at the tube of electrodes and circuit wiring is of the order of $1 \mu \mu \mathrm{f}$, neither ares nor deposits of the type under consideration occurred. The capacity in this case was but one-twentieth of that of the $1 \mathrm{~B} 24$ in its life test circuit. Upon addition of external capacity both arcs and deposits appeared, and the magnitude of the deposit increased for larger capacity. The arc as the mechanism of the deposit and the necessity for are energy storage in the distributed capacity were clearly established.

2. Decreasing cathode diameter with attendant rise in current density at the cathode resulted in an increasing deposit rate. The arcing rate increased at the same time.

3. The anode shape was not found to be a particularly important factor. The fact that the pointed anode had little effect on the anode deposits indicated that the deposited substance was uncharged.

4. Pulsing of the discharge increased the deposit rate over that obtained under direct-current conditions. It is probable that surface conditions necessary for the arc breakdown had arisen between current pulses in this case, while a direct-current discharge may have discouraged these conditions by constant cleaning of the cathode.

5. Water vapor played a decisive part in the formation of the deposits. Neither ares nor deposits were obtained in the tubes from which water vapor was omitted, indicating that this vapor may be essential to establishment of the surface conditions mentioned before. This fact, together with (1) and (4), is in accord with the findings of Jurriaanse and Druyvesteyn previously mentioned.

6. A most important factor is the cathode material. Eighteen-eight stainless steel represents a great improvement over kovar. As shown in the table previously, for only one of three $18-8$ cathodes were ares observed at all. This arcing was delayed for 60 $\mathrm{hr}$, and the small deposit that was formed was highly localized by comparison with those on the kovar electrodes. The remaining 18-8 cathodes showed negligible deposits. Sample tracings of kovar and 18-8 cathodes (fig. 4) clearly show the relative extent of deposit.

Since glass does not seal to $18-8$ steel, it was necessary to use a slip-on insulator, in this case porcelain, with this metal (fig. 3). The electrode design 
provided a narrow gap between the cathode and the ceramic to avoid a probable one point contact between cathode and ceramic in the absence of a perfect fit. Because all of the kovar cathode tests had been run with sealed-on glass insulation, a control test was made in which the relative deposit rates of glass- and porcelain-insulated kovar cathodes were measured (table 1, group V, tubes No. 29, 31, 33, 35). This control test showed a somewhat larger arc rate in the latter case, which at first thought appears contrary to the practice, generally accepted in tube development, of discouraging arc back by just such separation of a negative electrode from its insulation. The practice arose after the study by Issendorf, Schenkel, and Seeliger ${ }^{4}$ of the effect on arc back of various insulating materials in contact with a negative electrode. In the present case, the explanation of the apparent discrepancy probably lies in the difference of insulator material, and use of quartz, alundum, or even glass instead of porcelain might have avoided the discrepancy. The question was not pursued, since the improvement derived from use of 18-8 stainless steel cathodes far outweighed the disadvantage of the insulator choice, leaving no question as to the importance of the choice of cathode material.

The remedial steps suggested by this work are clear. Distributed capacity should be reduced as far as possible. Pulsing the discharge should be avoided when permissible, and the cathode current density should be as low as possible. Ideally, water vapor or other active gas or vapor should be omitted from the tube. This is an unobtainable ideal in most cases; an electronegative component is usually required in a TR tube in order to keep recovery time adequately short. The steps mentioned so far are generally limited in their feasibility by the particular application of the tube. One factor, the cathode material is usually not so determined. It has been shown that selection of this material is a critical factor in determining the life of a tube. It should therefore be possible to extend the life of TR tubes operating under the assumed conditions, where life is prematurely ended by keep-alive short circuit, by substitution of a ceramically insulated 18-8 stainless steel cathode for the customary glass insulated kovar cathode. The results described here might well be of value in the design of any electron tubes wherein high current density glow discharges are maintained between electrodes in close proximity.

The generous and valuable advice of John E. White, Chief of the Bureau's Electron Tube Laboratory, and of Wm. G. Dow of the University of Michigan is gratefully acknowledged.

Washington, May 11, 1950.

\title{
Test Mixtures for Distillation at Atmospheric and Reduced Pressure'
}

\author{
By Charles B. Willingham ${ }^{2}$ and Vincent A. Sedlak ${ }^{3}$
}

\begin{abstract}
In this paper are reported values for the separation factor for distillation for each of the three pairs of diethylbenzenes for pressures from 30 to $800 \mathrm{~mm} \mathrm{Hg}$. Also given are data on the refractive index as a function of composition for the system 1,2-diethylbenzene and 1,3-diethylbenzene.
\end{abstract}

A mixture of 1,2-diethylbenzene and 1,3-diethylbenzene was selected on the basis of boiling point, separation factor, and expected ideality for use as a test mixture for investigating the separating efficiency, at pressures in the range from 30 to $760 \mathrm{~mm}$ $\mathrm{Hg}$, of the rotary concentric-tube $[1,2]^{4}$ and other distilling columns [3]. As there is a difference of 0.0078 in the values of the refractive index, $n_{D}$ at $25^{\circ} \mathrm{C}$, of the two pure components, it is possible to analyze this mixture refractometrically within one and one-half percent of the composition from measurements of refractive index made to the nearest 0.0001 .

1 This investigation was performed at the National Bureau of Standards as part of the American Petroleum Institute Research Project 6 on the Analysis, Purification, and Properties of Hydrocarbons.

2 Now with the Mellon Institute, Pittsburgh, Pa.; formerly with the National Bureau of Standards.

${ }_{3}$ Now with the American Petroleum Institute Research Project 6 at the Carnegie Institute of Technology; formerly a Research Associate at the National Bureau of Standards.

4 Figures in brackets indicate the literature references at the end of this paper.
Accordingly, known mixtures of 1,2-diethylbenzene and 1,3-diethylbenzene, having compositions near 25,50 , and 75 percent of the former, were made up accurately by weight, by using samples of purified compounds corresponding to the material prepared for standard samples [4]. Measurements of the differences in the refractive index of these mixtures and of pure 1,2-diethylbenzene, with respect to pure 1,3-diethylbenzene, were made by using a modified Abbe-type precision refractometer [5]. The results, expressed as the difference between the refractive index of the mixture and of 1,3-diethylbenzene, are as follows:

For 1,3-diethylbenzene and 1,2-diethylbenzene, at $25^{\circ} \mathrm{C}$

$$
\begin{gathered}
n_{D}(\text { mixture })-n_{D}(1,3 \text {-diethylbenzene })= \\
0.00782 N-0.00008 N^{2},
\end{gathered}
$$

